\title{
Pathogenic Fungi - Neglected Infectious Agents? A Commentary on the Gambian Situation
}

\author{
Bolarinde Joseph Lawal* and Ousman Secka \\ Medical Research Council, the Gambia, West Africa
}

\begin{abstract}
This Commentary is aimed at examining the current attitude of healthcare providers towards pathogenic fungi, with more emphasis on The Gambia setting, and to make recommendations for better infectious disease diagnosis and management. It is a known fact that fungi are important infectious diseases causative agents, clinicians however hardly request for medical mycology laboratory tests either because they choose to treat empirically or due to lack of competent mycology laboratories around. Various literature reviewed shows that some signs and symptoms of fungal infections are similar to those caused by bacteria and viruses or both; therefore, there are possibilities of misdiagnosis and missed diagnosis of some diseases. Further mycological studies among Gambian population and inclusion of pathogenic fungal investigations in routine disease diagnosis should be considered.
\end{abstract}

\section{Keywords: Pathogenic fungi; Neglected; Infectious agents}

World Health Organisation (WHO) defines infectious diseases as diseases caused by pathogenic microorganisms, such as bacteria, viruses, parasites or fungi; the diseases can be spread, directly or indirectly, from one person to another [1]. Bacteria, parasites and viruses are more incriminated by health care providers for infectious diseases; fungi are often not investigated except in some cases of superficial and urogenital tract fungal infections. In 2001, a review of the scientific literature identified 1415 species of infectious organisms known to be pathogenic to humans, including 217 viruses and prions, 538 bacteria and rickettsia, 307 fungi, 66 protozoa and 287 helminthes and also showed that among the emerging pathogens, 9\% are fungi [2]. The same study showed that Emerging Pathogens are those that have appeared in a human population for the first time, or have occurred previously but are increasing in incidence or expanding into areas where they have not previously been reported, usually over the last 20 years [3].

Some types of fungal infections can be deadly if they are not identified and treated quickly, so early recognition is essential in order to reduce the risk of serious complications and save lives [4].

The fungi that cause infections in people are divided into three groups: yeasts, molds, and dimorphic fungi [5]. Some fungi are highly pathogenic and can establish a systemic infection in exposed individuals. Others only cause disease when the immune system is weak [6].

The frequency of severe systemic fungal diseases has increased in the last few decades. The clinical use of broad spectrum antibacterial drugs and immunosuppressive agents after organ transplantation, cancer chemotherapy, and advancements in surgery are associated with increasing risk of fungal infection [7].

According to Center for Disease Control (CDC), many people at risk for and suffering from fungal diseases live in resource-limited settings, where diagnosis and treatment of these infections can be challenging. These areas of the world often lack the laboratory infrastructure needed to diagnose fungal diseases, and limited availability of antifungal medications means that some patients who have fungal diseases including Cryptococci meningitis aren't able to receive the life-saving treatments they need [8]. Globally, it has been estimated that approximately 957,900 cases of Cryptococci meningoencephalitis occur each year, resulting in more than 600,000 deaths. The region with the highest number of estimated cases in 2006 was sub-Saharan Africa
(720,000 cases; range, 144,000 to 1.3 million), followed by South and Southeast Asia (120,000 cases; range, 24,000 to 216,000 ) [9]. In some countries with a high HIV prevalence, Cryptococci meningitis causes more deaths than tuberculosis [8]. Unfortunately, more emphasis is being placed on tuberculosis either as opportunistic infection among people living with HIV or co-infection with the virus. Opportunistic mycoses which occur primarily in immune compromised patients are caused by fungi such as Aspergillus species, Candida species and Cryptococcus neoformans Most of these fungi are saprophytic, living freely in soil or on decaying organic material [5] - possibility of high exposure. Despite widespread rollout of combined antiretroviral therapy, there are still up to 1 million deaths annually from Invasive Fungal Infections (IFIs), accounting for 50\% of all AIDS-related death. A historic failure to focus efforts on the IFIs that kill so many HIV patients has led to fundamental flaws in the management of advanced HIV infection [10]. A simple blood test can detect early Cryptococci disease in HIV-infected persons before they develop meningitis, creating opportunities to prevent this deadly disease [8].

Some signs and symptoms of fungal infections are similar to those caused by bacteria and viruses or both, therefore, the possibility of misdiagnosis and missed diagnosis of some diseases are inevitable. For instance in a study in hospitals from the south-western region of Nigeria where 230 acid fast bacilli negative sputum samples from 230 patients presenting with respiratory tract infections, cysts of Pneumocystis jirovecii, formerly known as $P$. carinii were observed in $15(6.5 \%)$ samples and polymerase chain reaction was positive for 29 (12.6\%) samples out of 230 samples examined. The author concluded that $P$. jirovecii should be included in diagnosis of these infections in that part of the world [11]. In The Gambia, a study looking at healthy young individuals concluded that infection with P. carinii was common [12].

*Corresponding author: Bolarinde Joseph Lawal, MRC Unit, The Gambia, Fajara, PO Box 273 Banjul, The Gambia, West Africa, Tel: (+220) 4495442/6; Fax: (+220) 4494154; E-mail: blawal@mrc.gm

Received January 14, 2015; Accepted March 31, 2015; Published April 02, 2015

Citation: Lawal BJ, Secka O (2015) Pathogenic Fungi - Neglected Infectious Agents? A Commentary on the Gambian Situation. J Med Microb Diagn 4: 180. doi:10.4172/21610703.1000181

Copyright: $\odot 2015$ Lawal BJ, et al. This is an open-access article distributed under the terms of the Creative Commons Attribution License, which permits unrestricted use, distribution, and reproduction in any medium, provided the original author and source are credited. 
Although, there are few data on fungi of medical importance especially in Sub Saharan countries, some pathogenic fungi such as Candida spp., Pneumocystis carinii, Aspergillus spp. etc. have been named as part of causative agents for upper or lower respiratory tract infections and other systemic invasive infections [5,13]. Mycology laboratories could therefore be helpful in diagnosis and management of some of these diseases. In addition, considering the fact that globally, Sub-Saharan Africa bears the highest HIV burden, with 24.7 [23.5-26.1] million people living with HIV in 2013 [14], the need for mycology laboratories within the region to help in opportunistic mycoses management among people living with HIV cannot be over emphasized.

While the Gambian Government is highly commended for the improved health financing which has greatly improved affordability and accessibility of healthcare to the populace [15], it should be noted that as at now comprehensive mycology laboratories are not available in the country most likely due to the fact that clinicians treat empirically. This pattern could however change if mycology laboratories are available. This could be exploited by the Government and international partners.

In conclusion, considering the fact that fungi are being classified among emerging infectious diseases agents, and the increasing cases of organ transplant, tuberculosis and possibly other diseases which enhance fungal opportunistic infections, fungal studies should be intensified in the country. Mycology investigations should be included in routine disease diagnosis, while more advanced organism identification such as molecular techniques should be considered.

\section{References}

1. (2015) WHO: Health Topics: Infectious Diseases.

2. Taylor LH, Latham SM, Woolhouse ME (2001) Risk factors for human disease emergence. Philos Trans R Soc Lond B Biol Sci 356: 983-989.
3. WHO (1997) Division of emerging and communicable diseases surveillance and control annual report - 1996. Geneva, World Health Organization, 1997 as cited in WHO 2003: Emerging Issues in Water and Infectious Diseases.

4. Centers for Disease Control and Prevention (2014) Fungal Diseases Outbreaks.

5. Ochei J and Kolhatkar A (2000) Medical Laboratory Science, Theory and Practice. Textbook; Tata McGraw-Hill Publishing Company Limited.

6. Fungal Infections: Types of Infection

7. Khan MSA, Ahmad I, Aqil F, Owais M (2010) Virulence and Pathogenicity of Fungal Pathogens with Special Reference to Candida albicans. In: Ahmad (ed.), Combating Fungal Infections.

8. Centers for Disease Control and Prevention (2014) National Center for Emerging and Zoonotic Infectious Diseases (NCEZID) Division of Foodborne Waterborne, and Environmental Diseases.

9. Cox GM, Perfect JR (2014) Epidemiology, clinical manifestations, and diagnosis of Cryptococcus neoformans meningoencephalitis in HIV-infected patients

10. James DA, Meintjes G, Brown GD (2014) A neglected epidemic: fungal infections in HIVIAIDS; Trend in Microbiology Journal, Published by Elsevier Ltd

11. Alli OA, Ogbolu DO, Ademola O, Oyenike MA (2012) Molecular detection of pneumocystis jirovecii in patients with respiratory tract infections $\mathrm{N} \mathrm{Am} \mathrm{J} \mathrm{Med}$ Sci 4: $479-485$

12. Wakefield AE, Stewart TJ, Moxon ER, Marsh K, Hopkin JM (1990) Infection with Pneumocystis carinii is prevalent in healthy Gambian children; Oxford Journals Medicine \& Health Transactions RSTMH 84: 800-802.

13. Cullen KA, Arguin PM; Centers for Disease Control and Prevention (CDC) (2014) Malaria surveillance--United States, 2012. MMWR Surveill Summ 63: 1-22.

14. (2014) World Health Organisation: HIVIAIDS Fact sheet $N^{\circ} 360$

15. National Health Policy of Republic of Gambia - "Health is Wealth" (2012-2020): Acceleration of Health Services and Universal Coverage; Ministry of Health and Social Welfare, Banjul, The Gambia 